\title{
The Effect of Highway Vibration to The Hills Slope Stability by an Integrated GPS-Vibration Data Processing
}

\author{
Achmad Ruchlihadiana Tisnasendjaja ${ }^{1}$, Hasanuddin Z. Abidin ${ }^{2}$, Dina A. Sarsito ${ }^{2}$, Imam A. Sadisun ${ }^{3}$, and Irwan Gumilar ${ }^{2}$ \\ ${ }^{1}$ Geodesy Department, Faculty of Technic, Winaya Mukti University, Pahlawan St. no. 69 Bandung 40123, West Java, Indonesia \\ ${ }^{2}$ Geodesy Research Group, Faculty of Earth Sciences and Technology, Bandung Institute of Technology, Ganesha St. 10, Bandung \\ 40132, West Java, Indonesia \\ ${ }^{3}$ Applied Geology Research Group, Faculty of Earth Sciences and Technology, Bandung Institute of Technology, Ganesha St. 10, \\ Bandung 40132, West Java, Indonesia
}

\begin{abstract}
Bandung-Jakarta, Indonesia highway have high density vehicles pass even often jammed. High activity of vehicles cause repeated vibrations and occur continuously. In case, the highway that divides the hills. The passing vehicles give rise repeatedly vibration and indicated disturbance of hillside slope stability. Vehicles vibration depend on speed, weight, number of vehicles and road construction materials. A method in question is counting a vehicle volume and determine the volume pattern of the vehicle. The magnitude of vibration is function of the object distance from the sources. The magnitude of the vibration effect is very dependent on the geological structure of hills formation. Hilly slope stability indicates experiencing interference if the object or material slope changes position or displacement. GPS observation give position changes and its displacement. The effect of Toll road vibration to slope stability is known by GPS and Vibration simultaneous measurement. Data acquisition used six unit GPS receivers and six unit vibration sensor which is installed on the hillside beside the highway. Integrated data processing techniques using Empirical Mode Decomposition (EMD). Integrated GPS-Vibration data are implemented to find actual displacement which are caused by highway vibration.
\end{abstract}

\section{Introduction}

Cipularang toll road is toll roads on Java, Indonesia. Opened on 2005, this road connects the JakartaCikampek Toll Road and the Padaleunyi Toll Road. The toll road is operated by PT Jasa Marga Tbk. The names come from abbreviation of Cikampek - Purwakarta Padalarang. This toll road stretches along the mountains so the track is going up and downhill and many bends and bridges. Using the toll road can save up to half the time because a shortcut between Bandung and Jakarta.

The volume of various types and weights of vehicles crossing the road, even on weekends and holidays there is a traffic jam. December 2015 data the average vehicle that passes is 40 thousand per day and each year has increased [2]. Mid-2018, the number of vehicles examined is 259 units, $39 \%$ of the average daily traffic volume, see below Figure 1. Of that number, the vehicles that were proven to be overloaded 153 units $(59.07 \%)$, over dimensions of 33 units $(12.74 \%)$, and normal 73 units $(28.19 \%)$. This road is the most populated toll road in Indonesia. In such conditions, the vehicle creates vibrations that take place continuously and repeatedly. This situation can trigger a disturbance in the surrounding slope stability. The volume of vehicles of the Cipularang toll road has increased steadily, see Figure 2. So monitoring the impact of vehicle vibrations on the slopes needs to be done.

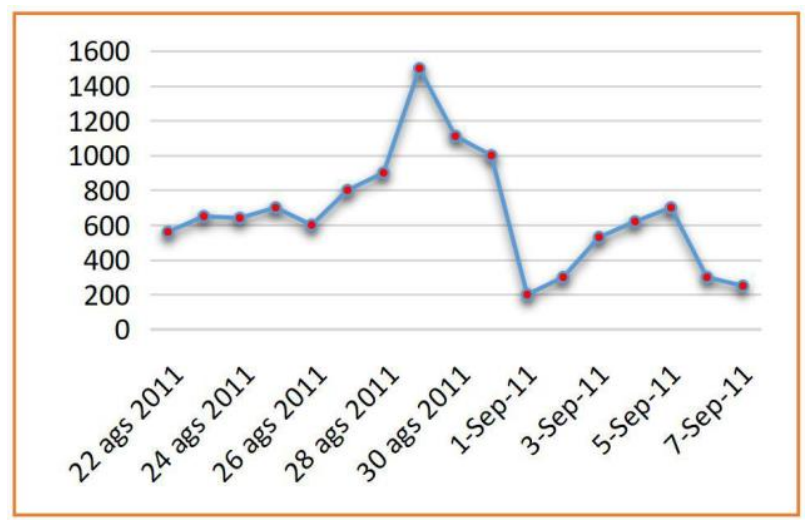

Fig. 1. Average Daily Traffic in 17 days at 2011 [1]

\footnotetext{
* Corresponding author: achmadrt87@ gmail.com
} 


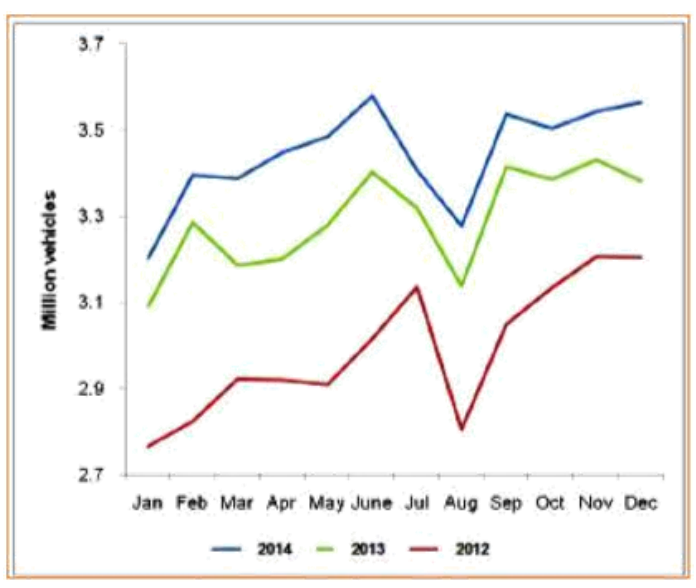

Fig. 2. Average Daily Traffic Increase [2]

Therefore, to determine the effect of vehicle loads passing through the toll road on slope stability, GPS observations and vibration measurements were carried out simultaneously.

\section{Data Acquisition}

The monitoring points are installed on the slopes around the toll road, see Figure 3. GNSS observations are carried out simultaneously with vibration measurements. Data acquisition is done simultaneously so that time synchronization can be done well.

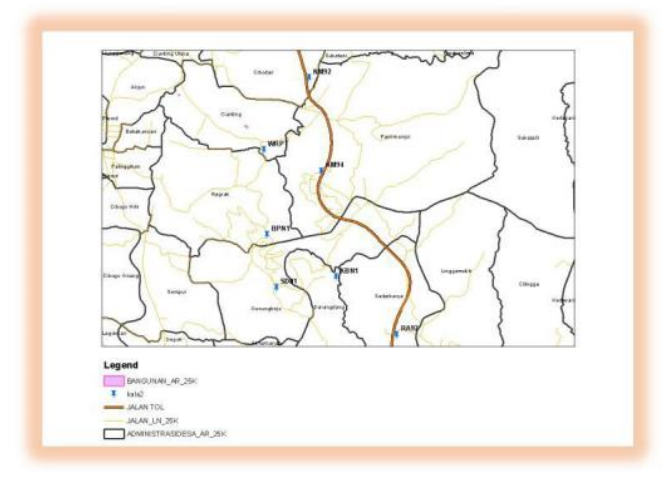

Fig. 3. Monitoring Points Distribution

First Period data acquisition was carried out at 6 monitoring points. Furthermore, the monitoring point is added to get a better distribution. The research area is between the Cipularang toll road (north) and the Darangdan Purwakarta highway (south). So the research area gets the vibrational influence of both.

\subsection{GNSS Observation}

GNSS observation used specification as follow:

Table 1. GNSS Observation Specification

\begin{tabular}{|ll|}
\hline Satellite Visibilty (GPS) & $: \min 6$ \\
\hline Elevation Mask & $: 15$ \\
\hline PDoP / GDoP & $:<8$ \\
\hline Interval Data & $: 5$ \\
\hline Observation Method & $:$ Static \\
\hline Duration & $:$ 4 hours \\
\hline Receiver Type & $:$ Dual Frequency \\
\hline
\end{tabular}

\subsection{Vibration Measurement}

The instrument used is a triaxial vibration sensor. Vibration sensor measurement where placed at the ground of monitoring point use specification as follow:

Table 2. Vibration Measurement Specification

\begin{tabular}{|ll|}
\hline Frequency & $\begin{array}{l}: 1 \mathrm{~Hz} \text { in high frequency mode } \\
0.1 \mathrm{~Hz} \text { in low frequency mode }\end{array}$ \\
\hline Duration & $\begin{array}{l}: 10-100 \text { (duration is adjusted to the duration } \\
\text { of GPS observation) }\end{array}$ \\
\hline Interval & $: 0.1$ \\
\hline Type -unit & $:$ LSM6DS3 Accelerometer $-\mathrm{m} / \mathrm{s}^{2}$ \\
\hline Resolution & $: 5.950928 \mathrm{E}-04$ \\
\hline Range & $: \max 78.4532$ \\
\hline Power & $: 0.9 \mathrm{~mW}$ \\
\hline
\end{tabular}

\section{Empirical Mode Decomposition (EMD)}

A new nonlinear technique, referred to as Empirical Mode Decomposition (EMD), has recently been pioneered by N.E. Huang et al. for adaptively representing nonstationary signals as sums of zero-mean Amplitude Modulation (AM) - Frequency modulation (FM) components [3].

All real processes that must be faced in practice are complex, as a rule, which consists of a large number of components. A chart of this type is therefore quite difficult to be analyzed as its components, when interacting with each other, mask and distort the regularities we would like to identify. This gives rise to a rightful desire to break down the process under consideration into individual components and analyze each of the components separately [7]. Analysis of individual components and consideration of contributions made in the existing process will help to better understand the processes that are running, as well as, can improve the reliability of estimates.

The term "decomposition" formally means the breaking down of a compound process or a composite material into separate constituent components. But in many areas related to analysis of different processes, signal analysis, analysis of various sorts of sequences. These functions are sort of artificially formed in the process of data decomposition but despite their "artificial" origin they allow for a deeper analysis of data helping to identify hidden patterns. There is a lot of various decomposition methods that can be applied in practice to a given sequence under consideration. These methods may have different underlying mathematical or empirical approaches, different degree of complexity and different areas of application [7].

The algorithm as proposed by Huang is based on producing smooth envelopes defined by local maxima and minima of a sequence and subsequent subtraction of the mean of these envelopes from the initial sequence. This requires the identification of all local extrema that are further connected by cubic spline lines to produce the 
upper and the lower envelopes. The procedure of plotting the envelopes is shown in Figure 4.

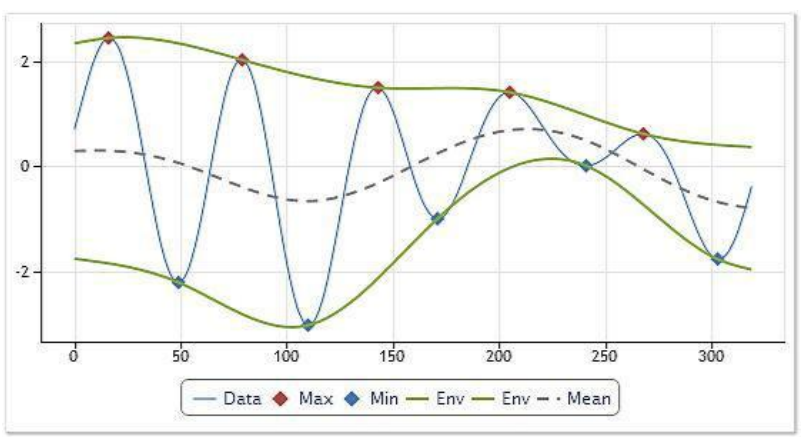

Fig. 4. Plotting the envelopes and their mean [7]

Emd decomposes a signal $\mathrm{X}(\mathrm{t})$ into $\mathrm{k}$ number of intrinsic mode functions (IMF), and residual rk(t) using the sifting process. A brief overview of the sifting process, listed in [3] and [4], is as follows [8]:

1. Find local maxima and minima for signal $X(t)$ to construct an upper envelope $s_{+}(t)$, and a lower envelope $s-(t)$.

2. Compute mean envelope for $i^{t h}$ iteration, $m_{k, i}(t)$,

$$
m_{k, i}(t)=\frac{1}{2}\left[s_{+}(t)+s_{-}(t)\right]
$$

3. With $c_{k}(t)=X(t)$ for the first iteration, subtract mean envelope from residual signal,

$$
c_{k}(t)=c_{k}(t)-m_{k, i}(t)
$$

If $c_{k}(t)$ does not match the criteria of an IMF, steps 4 and 5 are skipped. The procedure is iterated again at step 1 with the new value of $c k(t)$.

4. If $c_{k}(t)$ matches the criteria of an IMF, a new residual is computed. To update the residual signal, subtract the $k^{\text {th }}$ IMF from the previous residual signal,

$$
r_{k}(t)=r_{k}-1(t)-c_{k}(t)
$$

5. Then begin from step 1 , using the residual obtained as a new signal $r k(t)$, and store $c k(t)$ as an Intrinsic Mode Function (IMF).

For $\mathrm{N}$ intrinsic mode functions, the original signal is represented as [8],

$$
X(t)=\sum_{i=1}^{N} c_{i}(t)+r_{N}(t)
$$

Sift Relative Tolerance is a Cauchy type stop criterion proposed in [6]. Sifting stops when current relative tolerance is less than SiftRelativeTolerance. The current relative tolerance is defined as [8],

$$
\text { RelativeTolerance } \triangleq \frac{\| c(t) \text { previous }-c(t) \text { current } \|^{2}}{\| c(t) \text { current } \|^{2}}
$$

Energy ratio is the ratio of the energy of the signal at the beginning of sifting and the average envelope energy [4].
Decomposition stops when current energy ratio is larger than MaxEnergyRatio. For k IMFs, EnergyRatio is defined as [8],

$$
\text { EnergyRatio } \triangleq 10 \log _{10}\left(\frac{\|X(t)\|^{2}}{\left\|r_{k}(t)\right\|^{2}}\right)
$$

\subsection{GNSS Data Processing}

GNSS data processing uses a kinematic method. GNSS survey data for 30-60 minutes is processed as initiation. after that data processing is done by kinematic algorithm. the goal is that we can get positions every 5 seconds. Among the 6 monitoring points, one is used as a reference point. By considering the stability of the point position against vehicle vibrations on the toll/highway road, the point above the construction of the $\mathrm{km} 97$ bridge is used as a reference. From the distribution of the position of the monitoring point, two points were chosen as the focus of the analysis, namely the point on the edge of the km95 toll road ('msjd97') and the point in the center of the research area, which has a distance of $1.4 \mathrm{~km}$. The point in question is the ' $\mathrm{kbnl}$ ' point installed in the middle of the cropland.

The results of GNSS processing use a topocentric coordinate system (east, north, up) and find accelerations to match the vibration measurement system. In order for the analysis to be carried out, the suitability of GNSS observation and vibration time must be the same, following the intended time suitability.

Table 4. Time Suitability GNSS and Vibration Measurement

\begin{tabular}{|c|c|c|c|c|}
\hline & \multicolumn{2}{|c|}{ kbn1 } & \multicolumn{2}{c|}{ msjd97 } \\
\hline & Start & End & Start & End \\
\hline $\begin{array}{c}\text { GNSS } \\
\text { OBSV }\end{array}$ & $11: 20: 38$ & $12: 33: 08$ & $11: 21: 03$ & $13: 58: 23$ \\
\hline VIBRATION & $11: 42: 21$ & $12: 33: 08$ & $11: 43: 49$ & $12: 52: 06$ \\
MEAS & & & & \\
\hline
\end{tabular}

Field data acquisition begins and ends with the same time. because there is a problem with the instrument, then time synchronization obtained as listed in table 3 . So the analysis of the results of kbn1 and msjd97 points can only be done with signal decomposition patterns. The following are sequentially presented by processing result at point kbn1.

Plotting of kbn1 GNSS data (ae, an, au) 

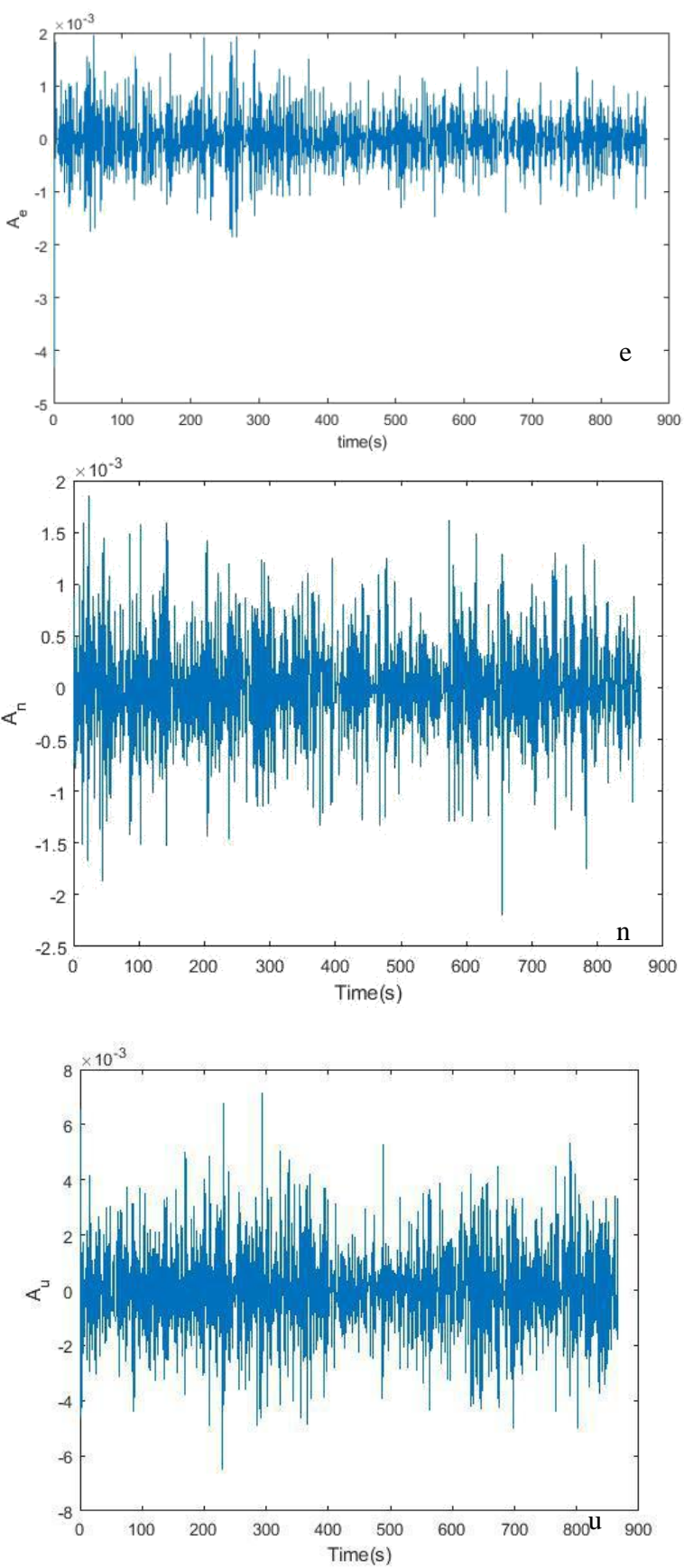

Fig. 5. Time vs Amplitude (e, n, u) GNSS Data of 'kbn1'

Plotting of kbn1 Emd-Imf (e, n, u)

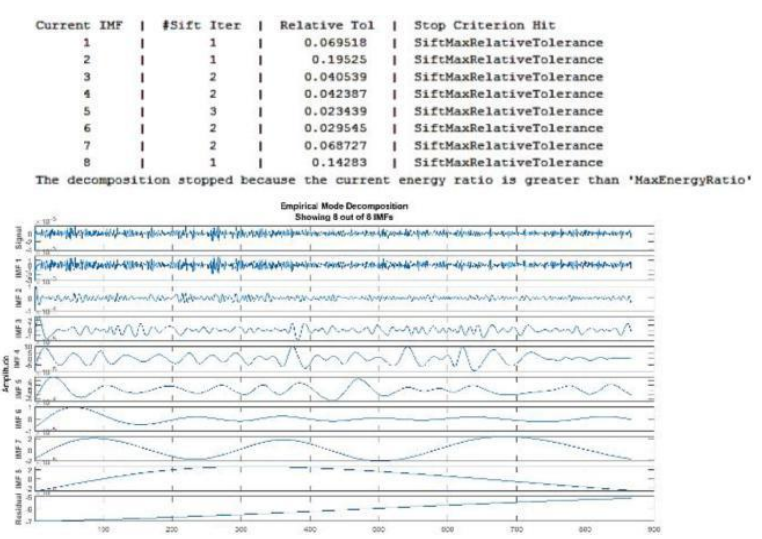

Fig. 6. Emd-Imf of 'kbnl'_e

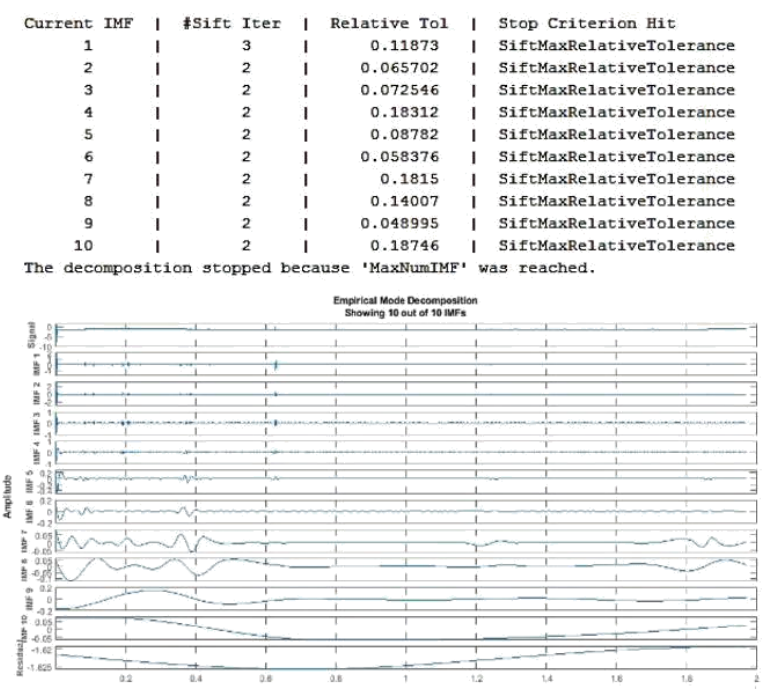

Fig. 7. Emd-Imf of 'kbn1' $n$

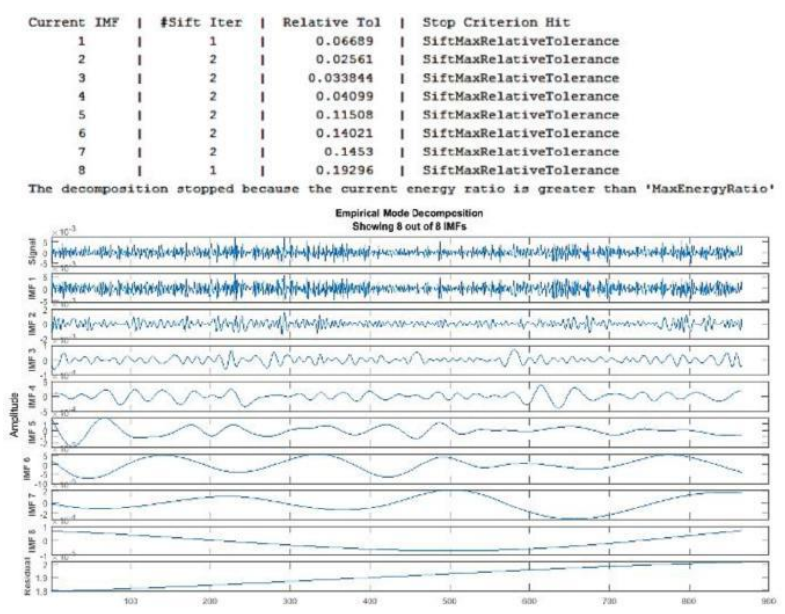

Fig. 8. Emd-Imf of ' $k b n 1$ '

Further point is msjd97:

Plotting of msjd97 GNSS data (ae, an, au)

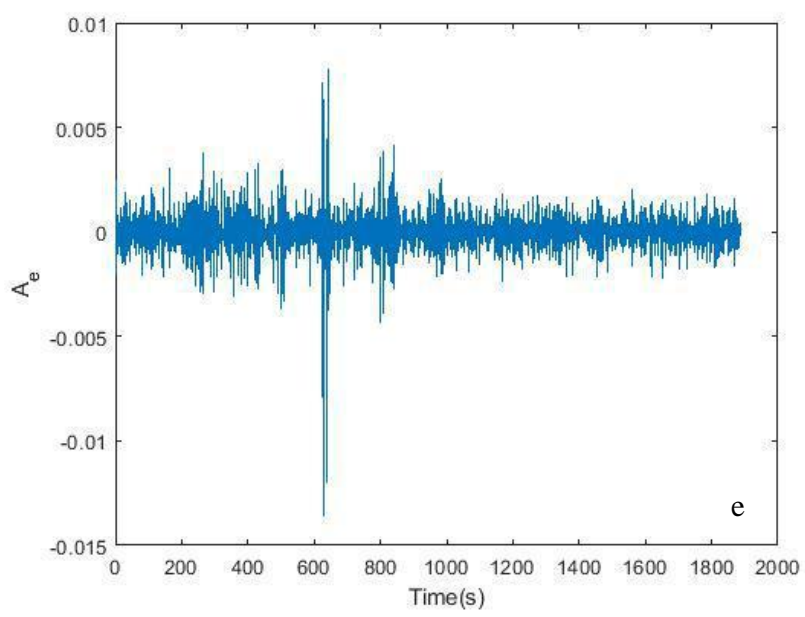



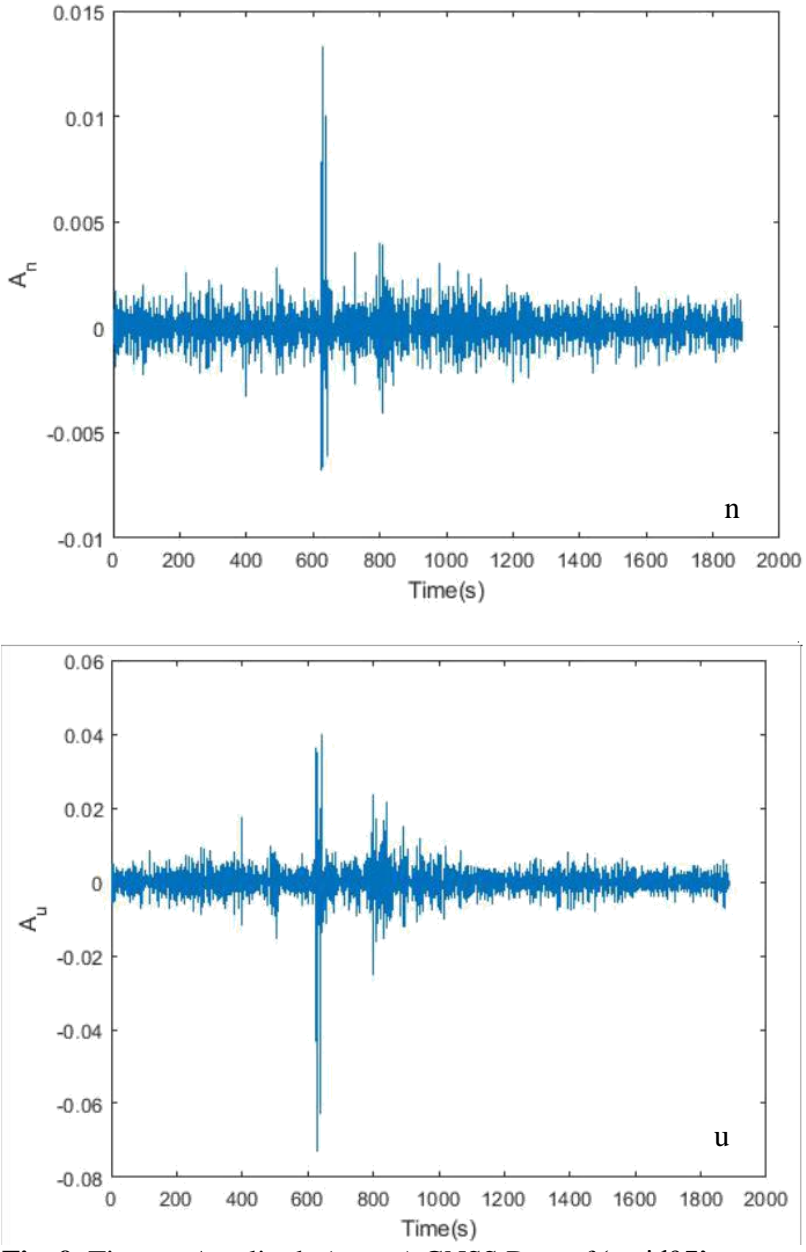

Fig. 9. Time vs Amplitude (e, n, u) GNSS Data of 'msjd97'

Plotting of msjd97 Emd-Imf (e, n, u)

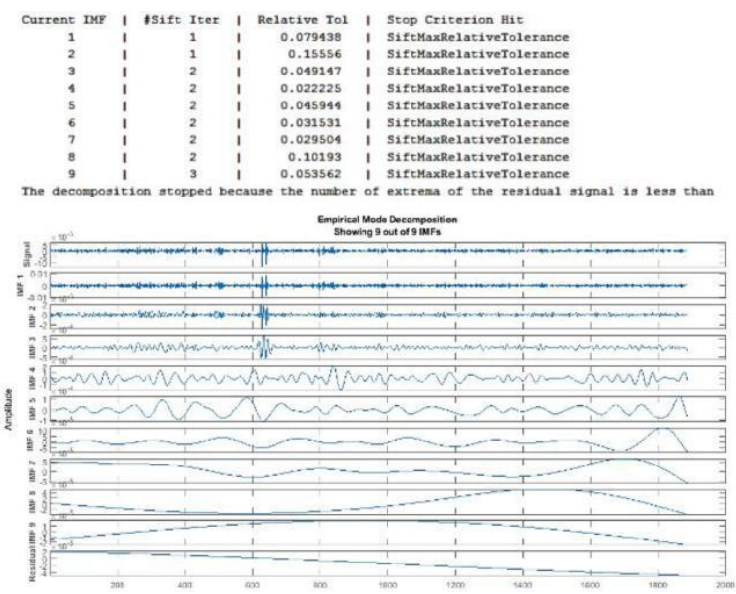

Fig. 10. Emd-Imf of 'msjd97'_e

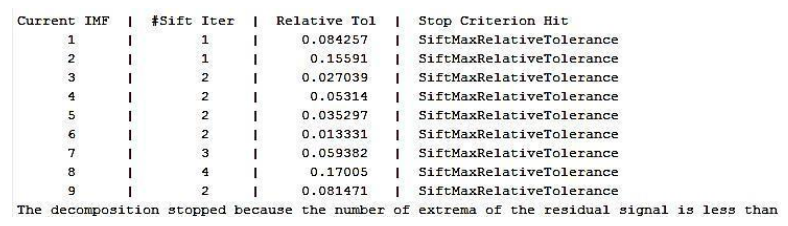

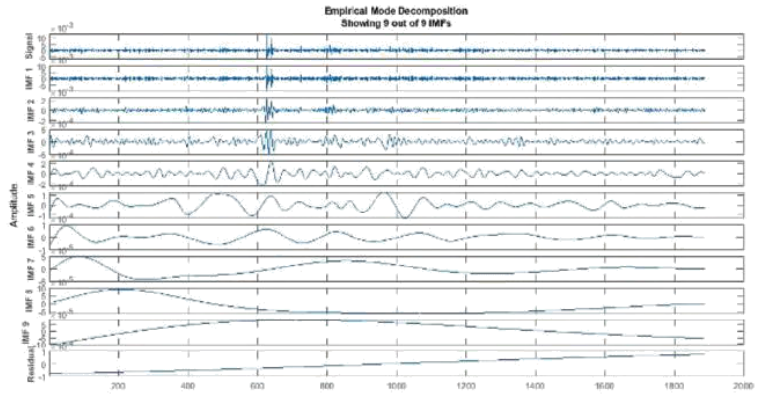

Fig. 11. Emd-Imf of 'msjd97'_n

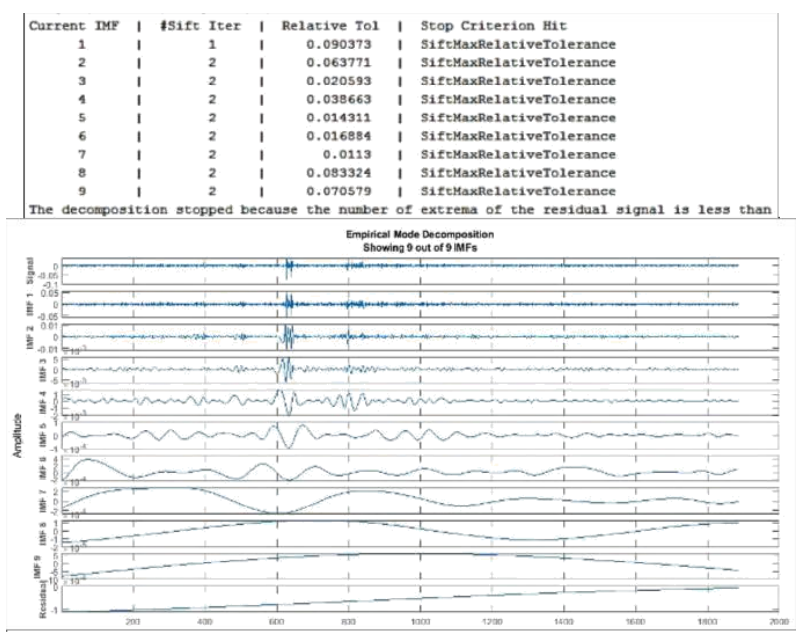

Fig. 12. Emd-Imf of 'msjd97'_u

\subsection{Vibration Data Processing}

Vibration measurement uses a triaxial vibration sensor so that the acceleration data has a value of 3 axes $(x, y, z)$. The unit is $\mathrm{m} / \mathrm{s} 2$. For analysis, the data process is carried out for each axis, as well as gnss data. The following are the results of processing for vibrations data at kbn1 and msjd97 point.

Plotting of kbn1 vibrations data $(\mathrm{x}, \mathrm{y}, \mathrm{z})$
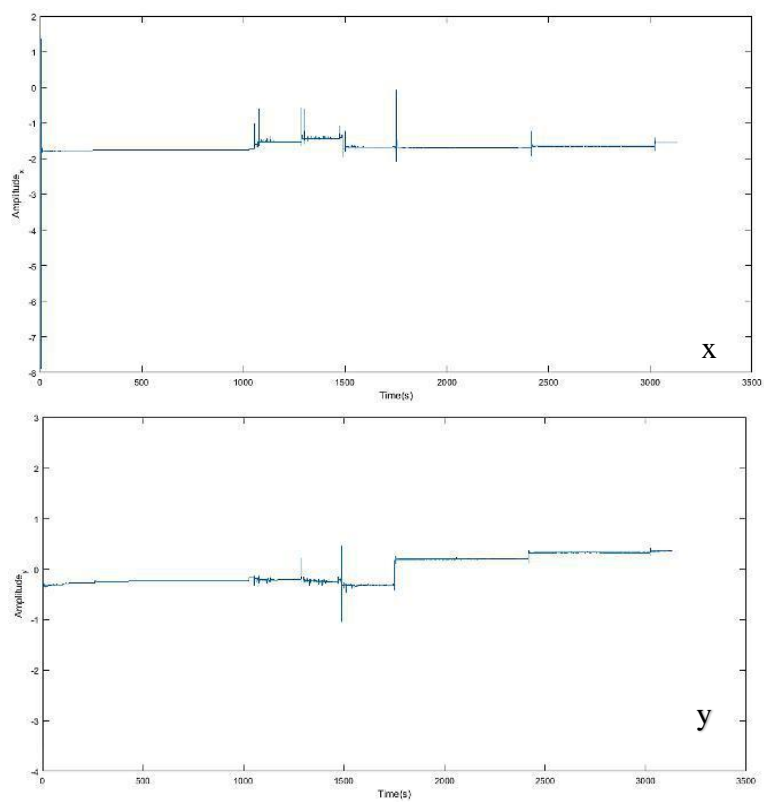


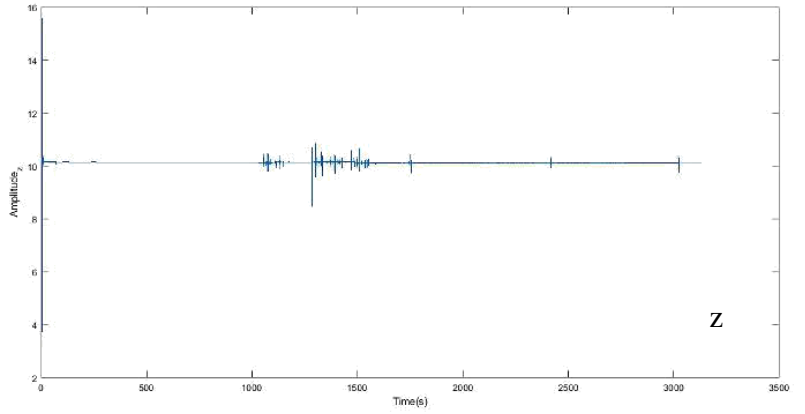

Fig. 13. Time vs Amplitude (x,y, z) Vibration Data of 'kbn1'

Plotting of kbn1 Emd-Imf (x,y, z)

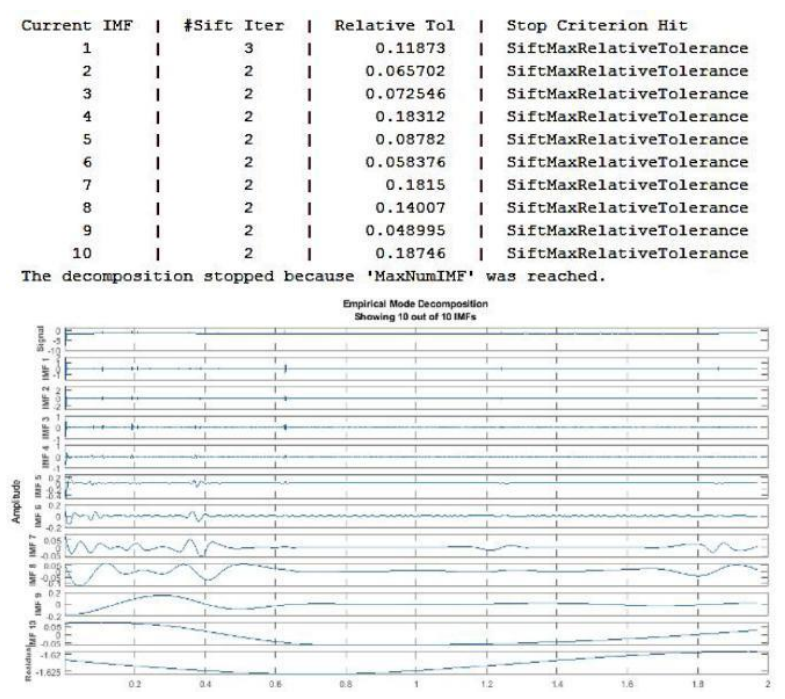

Fig. 14. Emd-Imf of ' $k b n 1$ '

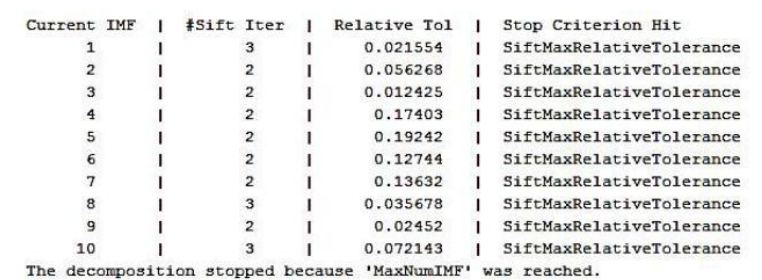

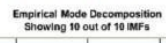

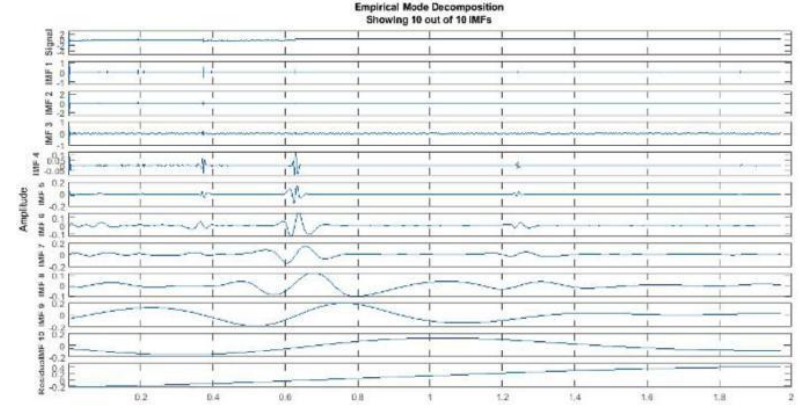

Fig. 15. Emd-Imf of ' $k b n 1$ ' _y

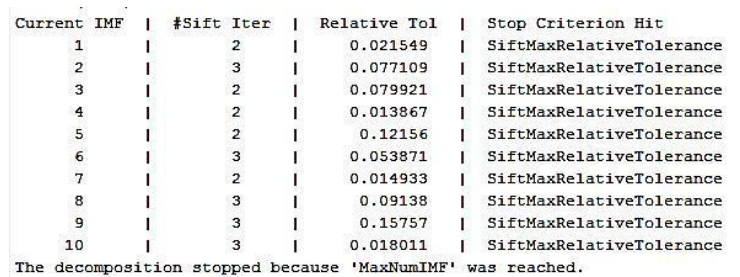

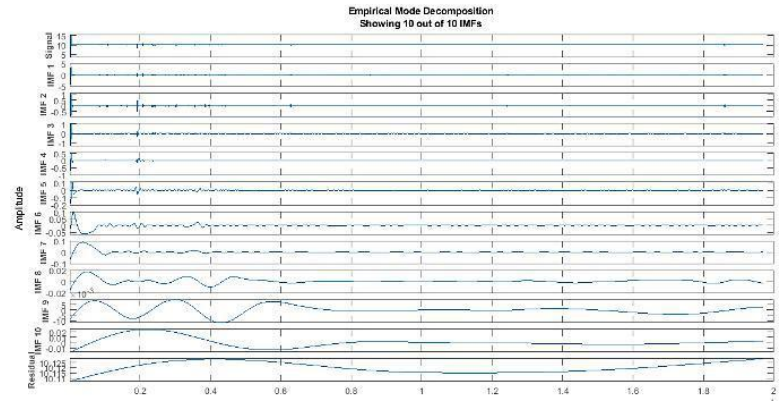

Fig. 16. Emd-Imf of ' $k b n 1$ '

The next point:

Plotting of msjd97 vibrations data $(x, y, z)$
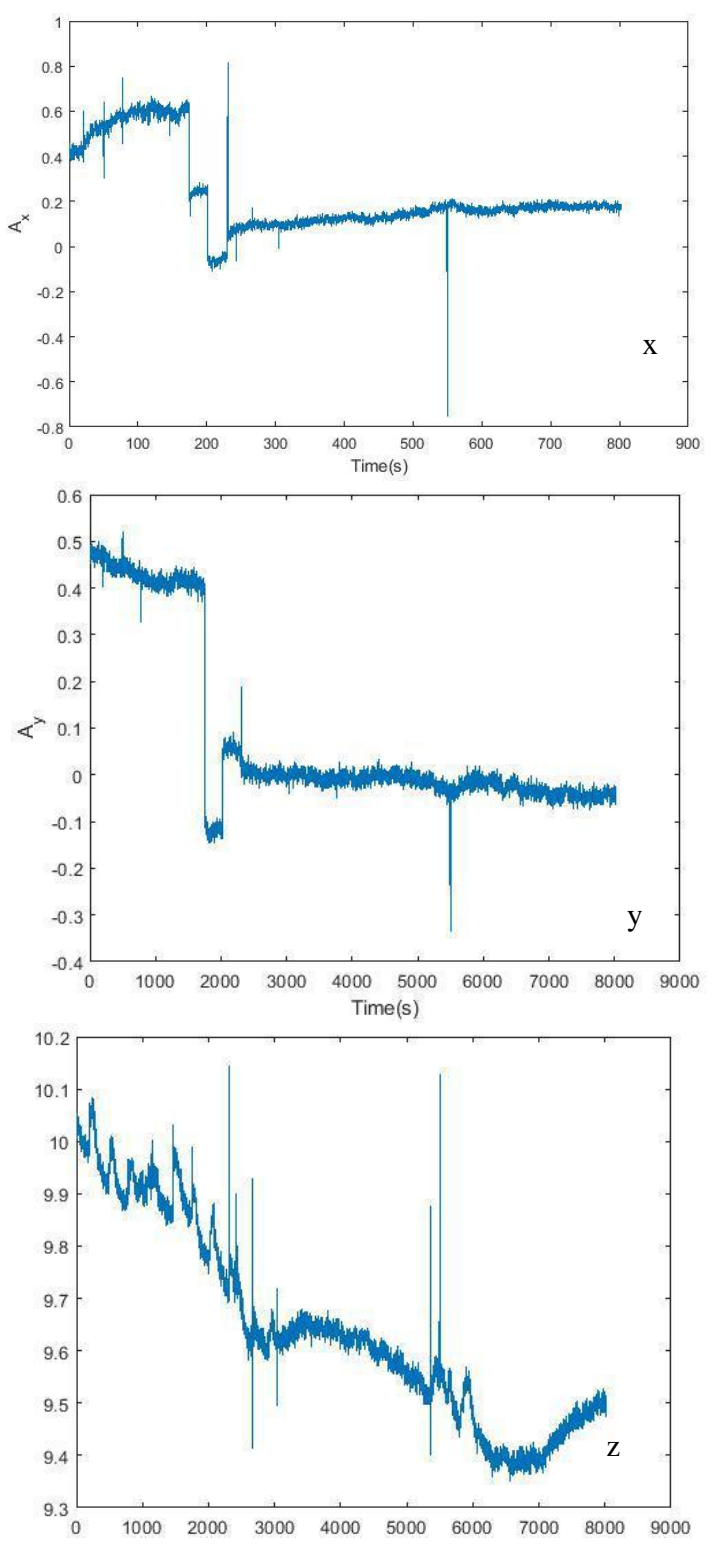

Fig. 17. Time vs Amplitude (x,y, z) Vibration Data of 'msjd97'

Plotting of msjd97 Emd-Imf (x, y, z) 


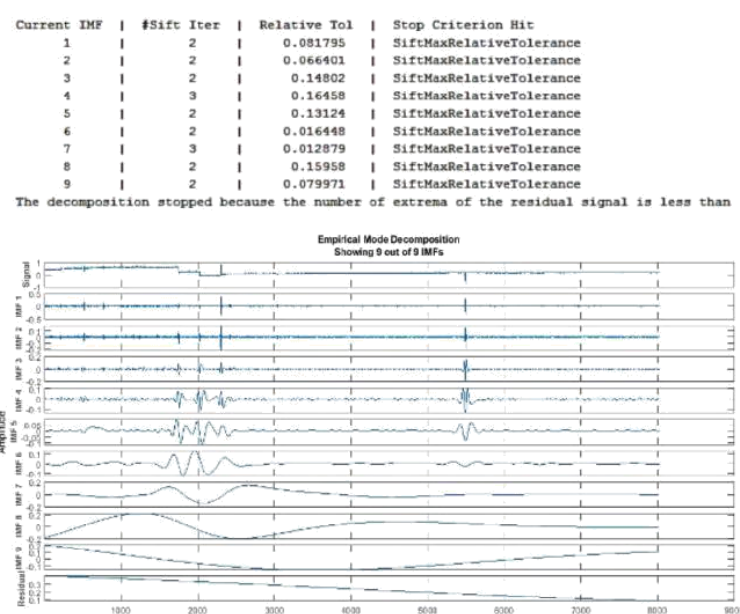

Fig. 18. Emd-Imf of 'msjd97'_x

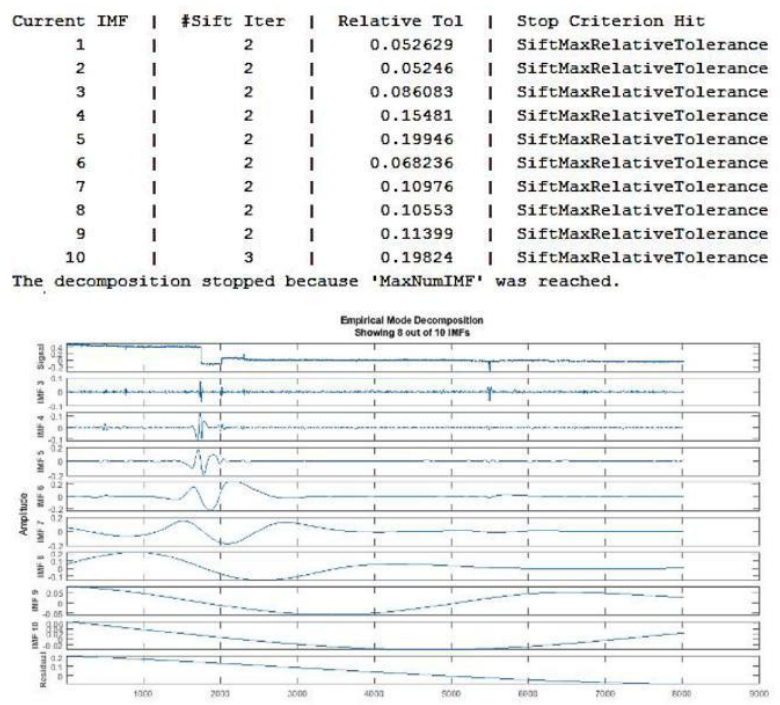

Fig. 19. Emd-Imf of 'msjd97'_y
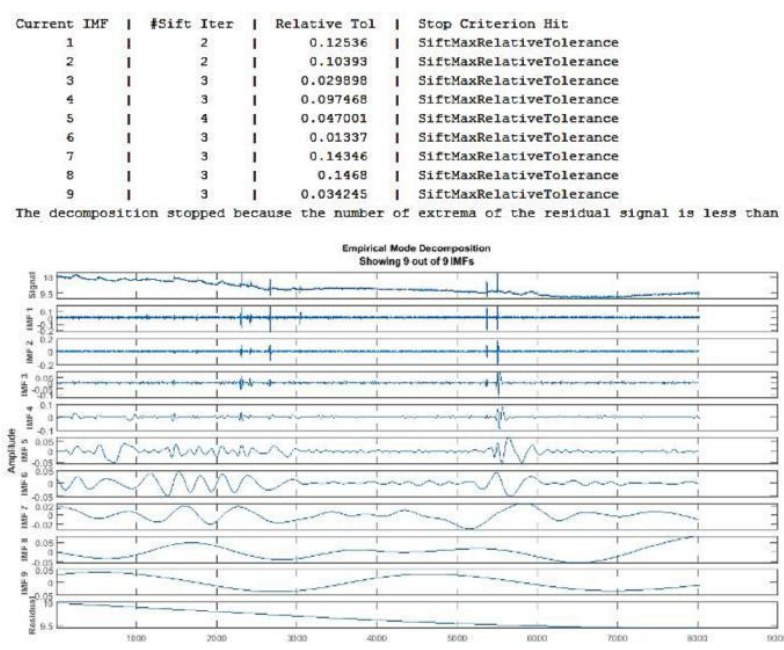

Fig. 20. Emd-Imf of 'msjd97' $z$

\subsection{Indication of Vibration Effect of on Slope Stability}

The figure below is presented with vector changes resulting from periodic GNSS observations from 1 September 2018 to 6 October 2018.

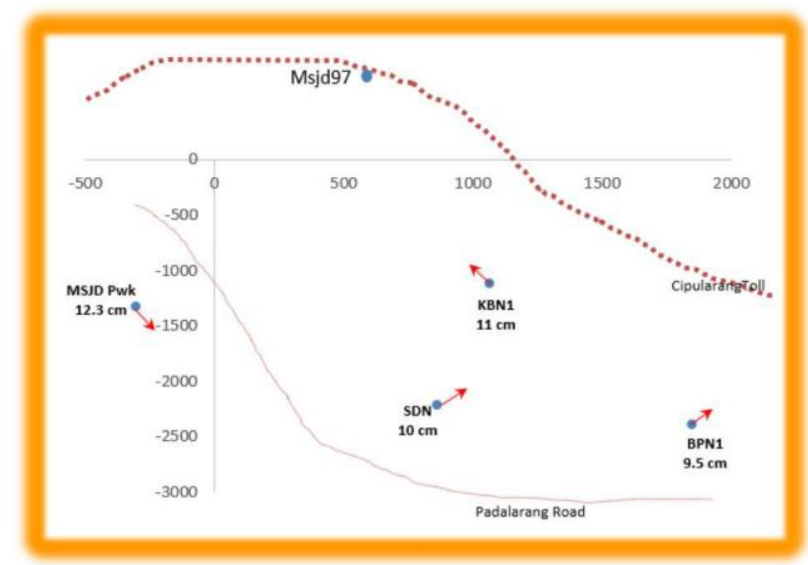

Fig. 21. Average Daily Traffic Increase [2]

\section{Discussion and Conclusion}

The following conclusions are based on the assumption that the observations of GNSS and Vibration are carried out for 2 periods and at the same time.

1. Figures 5 to 12 show changes in acceleration resulting from variations in GNSS position during observation. That variation can be indicated as the influence of vibrations on the road.

2. Figures 13 to 20 show changes in acceleration resulting from variations in vibration during observation. That variation can be indicated as the influence of vehicle activity on the road

3. That indeed at points observed both the observations of GNSS and the vibrations of material slope movements occur.

For further studies, indications of the conclusions above will be examined further.

\section{References}

1. Manggala G., Kecelakaan di Tol Cipularang: Human Error atau Kondisi Jalan? Sebuah Tool Statistik Sederhana Bisa Membantu, https://gdmanggala.wordpress.com/2011/09/18/ (2011).

2. JSMR, Investor Summit and Capital Market Expo 2015, Jasa Marga Indonesia Highway Corp, 19 (2015). 
3. N.E. Huang, Z. Shen, S.R. Long, M.L. Wu, H.H. Shih, Q. Zheng, N.C. Yen, C.C. Tung and H.H. Liu, The empirical mode decomposition and the Hilbert spectrum for nonlinear and non-stationary time series analysis. Proceedings of the Royal Society of London. Series A: Mathematical, Physical and Engineering Sciences, (1998).

4. G. Rilling, Flandrin, P. Flandrin and P. Gonçalves, On empirical mode decomposition and its algorithms. IEEE-EURASIP workshop on nonlinear signal and image processing, p.8-11, (2003).

5. Rato, R.T., Ortigueira, Manuel, Batista, and Arnaldo, On the HHT, its problems, and some solutions, Mechanical Systems and Signal Processing, p.1374-1394, (2008).

6. Wang, Gang, Chen, Xianyao, Qiao, Fang-Li, Wu, Zhaohua, Huang, Norden. On Intrinsic Mode Function, Advances in Adaptive Data Analysis, p. 277-293, (2010).

7. Victor, Introduction to the Empirical Mode Decomposition Method, MQL5 Articles, p.1-13, (2012).

8. https://www.mathworks.com/help/signal/ref/emd.ht ml\#mw 01f39430-58d5-4b1f-b2f7-285ffeeca163

9. S.Maheswari and A.Kumar, Empirical Mode Decomposition : Theory \& Applications, International Journal of Electronic Engineering, Vol. 7, p. 873-878, (2014) 